\title{
Políticas para a inclusão: estudo realizado em uma Escola Estadual de Belo Horizonte
}

\section{Policies for inclusion: study in a State School in Belo Horizonte}

\author{
Maria Auxiliadora Monteiro Oliveira ${ }^{1}$ \\ Sandra Freitas de Souza ${ }^{2}$
}

\begin{abstract}
RESUMO
Este trabalho, centrado nas Políticas Públicas para a Educação Inclusiva, enfatiza a formação de professores para trabalharem com alunos que apresentam necessidades educacionais especiais. A pesquisa, realizada em 2007/2008, em uma Escola Estadual de Belo Horizonte, objetivou investigar a capacitação de docentes para essa modalidade de educação e avaliar o processo de inclusão dos mencionados alunos, em uma escola estadual de BH. Metodologicamente, optou-se pela denominada pesquisa "QualiQuanti”, na qual se aplicou um questionário que desenhou o perfil de 25 professoras da escola. Em termos qualitativos, foram entrevistadas 10 docentes, a diretora da escola e a gerente da Diretoria de Educação Especial (DEEP). Em síntese, foram estes os dados coletados: todas as professoras eram favoráveis à Educação Inclusiva; nenhuma delas tinha capacitação para trabalhar com essa educação e, apenas duas conheciam um pouco da legislação sobre a Educação Inclusiva; todas afirmaram tanto ter dificuldade de lidar com os referidos alunos quanto ser significativa a evasão escolar dos mesmos.
\end{abstract}

Palavras-chave: educação inclusiva; formação de professores para a inclusão; políticas públicas para a educação inclusiva.

${ }^{1}$ Doutora em Educação pela Universidade Estadual de Campinas (UNICAMP). Pós-Doutora em Educação pela Universidade do Porto e pela UNICAMP. Professora do Programa de Pós-Graduação em Educação da Pontifícia Universidade Católica de Minas Gerais (PUC/MG), Brasil.

${ }^{2}$ Mestre em Educação pela Universidade Católica de Minas Gerais (PUC/MG). Supervisora Pedagógica da Escola Estadual Pestalozzi e Professora Universitária da Faculdade Pitágoras e da Universidade Presidente Antônio Carlos, Brasil. 


\begin{abstract}
This article, focusing on Public Policies for Inclusive Education, emphasizes the formation of teachers to work with students who have special educational needs. The survey, conducted in $2007 / 2008$ in a State School in Belo Horizonte aimed to investigate the training of teachers for the education, evaluate the process of inclusion of students mentioned in a government school in BH. Methodologically, we focused on the questionnaire that drew the outline of 25 teachers from the school. Ten teachers were interviewed, the school director and the manager of the Directorate of Special Education (DEEP). In synthesis, these data were collected: all teachers were in favor of Inclusive Education, none of which had capacity to work with this education, only two knew a bit of legislation on inclusive education, all said both have difficulty dealing with those students, and that large dropout of them.
\end{abstract}

Keywords: Inclusive education; teacher training for inclusion, public policies for inclusive education.

\title{
Introdução
}

Este trabalho analisa as políticas de inclusão escolar para alunos com necessidades educacionais especiais, em uma escola estadual de Belo Horizonte.

Ao se contemplar o campo das políticas, concorda-se com Ball (1997), no sentido de que nenhuma política é neutra, pois se insere em um campo de representações codificadas e recodificadas, engendradas em determinado contexto histórico e espaço geográfico, através de conflitos, lutas e correlações de forças. As políticas voltadas para a inclusão de alunos com necessidades educacionais especiais têm gravitado em um campo contestado, muito disputado, à semelhança do que vem ocorrendo, por exemplo, no âmbito das questões referentes ao gênero e à raça.

Para se compreender a complexidade das Políticas Educativas Inclusivas, inicia-se fazendo uma retrospectiva sucinta do seu desenvolvimento no Brasil. Em seguida, expõe-se a pesquisa realizada e, finalmente, são tecidas algumas considerações finais.

\section{Educação inclusiva e a formação de professores}

No Brasil, os estudos e as políticas públicas para a educação especial/ inclusiva são bastante recentes. Assim, só a partir da segunda metade do século $\mathrm{XX}$ os documentos normativos começaram a fazer referência à educação em 
pauta. A primeira Lei de Diretrizes e Bases (LDB), Lei n. 4.024/61 dispôs que a educação é direito de todos, recomendando a integração da educação especial ao Sistema Regular de Ensino. A Lei 5692/71 reafirmou a necessidade de se conferir um tratamento adequado aos alunos com necessidades educacionais especiais.

Em 1981, foi instituído pela ONU (Organizações das Nações Unidas) o Ano Internacional das Pessoas com Deficiência, que defendeu a igualdade de oportunidades para todos. A partir de então, foram formuladas ações que provocaram a ruptura com a atitude de benevolência e a priorização de uma posição política, centrada no direito e no acesso à cidadania dos alunos com necessidades educacionais especiais (OLIVEIRA; AMARAL, 2004).

A Constituição Federal de 1988 e o Estatuto da Criança e do Adolescente (Lei n. 8.069, de 13/07/90) determinam direitos para as pessoas especiais. A Constituição, no seu artigo 208, inciso III, explicita como dever do Estado o atendimento educacional especializado às pessoas com deficiência, preferencialmente, na Rede Regular de Ensino.

Em 1988, a Lei 7853/89 assegurou vários direitos aos alunos com necessidades educacionais especiais: matrícula compulsória em escolas públicas e privadas de ensino; oferta obrigatória de Programas de Educação Especial em estabelecimentos públicos de ensino; oferta de Programas de Educação Especial; oferta de material escolar, merenda e bolsa de estudos. Em 1990, o Brasil participou da Conferência Mundial de Educação para Todos, na qual foi aprovada a Declaração Mundial de Educação para Todos, que enfatizou a importância da educação para os sujeitos excluídos social e educacionalmente.

O Decreto n. 914/93 estabeleceu as Diretrizes da Política Nacional para a Integração da Pessoa com Deficiência, que garantiu, aos sujeitos especiais, direitos em todas as instâncias governamentais, ou seja, saúde, educação, trabalho, seguridade social, habitação, cultura, esporte, lazer, qualificação e inserção profissional.

Em 1994, a Conferência de Salamanca contemplou questões relativas à educação especial, destacando entre elas que alunos com necessidades educacionais especiais deveriam ter acesso às escolas regulares, usando uma pedagogia que atenda as suas necessidades (BRASIL, 1994). Também, em 1994, foi veiculada a Portaria n. 1.793/94, que recomendou a inclusão da disciplina "Aspectos éticos, políticos, educacionais e normalização e integração de alunos com necessidades educacionais especiais", nos currículos dos Cursos de Pedagogia, Psicologia, em todas as licenciaturas e em outros cursos superiores.

Em 1996, foi promulgada a LDB (Lei $\left.n^{\circ} .9394 / 96\right)$, que dedica o capítulo $\mathrm{V}$ à educação especial, sendo que o artigo 58 enfatiza que essa modalidade 
de educação deve ser oferecida na Rede "Regular" de Ensino, para os "portadores" de necessidades especiais, estabelecendo, nos incisos de I a V, condições que devem ser asseguradas pelos sistemas de ensino ${ }^{3}$. Contudo, pesquisas realizadas e, especialmente, a aqui retratada, evidenciam uma grande diferença entre o que é requerido no discurso normativo e o que vem ocorrendo na prática concreta.

Os Parâmetros Curriculares Nacionais - Adaptações Curriculares, Estratégias para a Educação de Alunos com Necessidades Especiais - explicitam a necessidade de esses alunos terem acesso aos conhecimentos necessários à vivência cidadã.

Em 1999, a Conferência Internacional para a Eliminação de Todas as Formas de Discriminação contra as Pessoas com Deficiência, ocorrida na Guatemala, motivou a veiculação do Decreto n. 3956/2001, que dispôs sobre a eliminação de todas as formas de discriminação e a necessidade de promover a integração social plena dos alunos com necessidades educacionais especiais. As Diretrizes Nacionais para a Educação de Pessoas com Necessidades Educacionais na Educação Básica (Resolução/CNE/CEB n. 2/2001) determinou que os Sistemas de Ensino matriculassem todos os alunos, independentemente de deficiências e diferenças, assegurando as condições necessárias à inclusão, recomendando também a capacitação dos professores para a educação inclusiva.

O Plano Nacional de Educação, Lei n. 10.172/2001, dispôs sobre: a inclusão do aluno especial no sistema regular de ensino; o atendimento de casos específicos, em classes e escolas especializadas; o apoio das escolas especiais às escolas comuns; a qualificação dos docentes; e a oferta de cursos de formação e de especialização em universidades.

Para se concretizar essa educação inclusiva preconizada, é preciso assegurar condições físicas e infraestruturais, recursos especializados e capacitação dos professores, tratando-se, assim, de uma tarefa difícil, pois requer mudança de mentalidade da grande maioria dos gestores e um grande investimento financeiro. A instauração dessa prática inclusiva, segundo Magalhães (2006, p. 359), requer a adoção

[...] de uma concepção de prática pedagógica diferenciada e inclusiva que está ancorada na tese de que a heterogeneidade dos alunos deve ser

\footnotetext{
${ }^{3}$ Assim, esses incisos apregoam ser necessário assegurar: currículos, métodos, técnicas, recursos educativos e organização específicos, para atender às suas necessidades; terminalidade específica para os que não puderam atingir o nível exigido para a conclusão do ensino fundamental, em virtude de suas deficiências; professores com especialização adequada em nível médio ou superior, para atendimento especializado, bem como professores do ensino "regular" capacitados para promover a integração em classes comuns.
} 
respeitada e, portanto, o aluno com deficiência tem direito e necessidade de participar e de ser considerado membro ativo, no interior da comunidade escolar.

Assim, a educação inclusiva requer modificações substantivas que envolvem: questões inerentes às políticas de inclusão, à flexibilização curricular, à preparação da escola comum ${ }^{4}$ para receber alunos especiais, à utilização de técnicas e recursos apropriados e à capacitação docente.

Entretanto, constata-se que existe uma separação entre o discurso e a prática, pois as práticas são, geralmente, pseudoinclusivas, podendo confundir os professores a respeito de sua concepção/ação no campo da inclusão, sobretudo, porque eles, geralmente, não sendo capacitados, não têm condições de fazer o discernimento (MAGALHÃES, 2006).

O referido discurso laudatório, pode ser observado no Parecer n. 424/ 2003, do Conselho Estadual de Educação de Minas Gerais, que expõe, mais do que real, uma situação idealizada.

Segundo constatado em estudos e pesquisas, as escolas inclusivas e integradoras preparam seus professores para trabalharem com a diversidade; reduzem o número de alunos por turma, se necessário; distribuem os alunos com necessidades educacionais especiais nas turmas, evitando-se a sua concentração em uma única turma; estimulam a cooperação e solidariedade entre alunos; trabalham com sistemas de monitorias de alunos; os prédios escolares são acessíveis, sem barreiras arquitetônicas e atitudes preconceituosas ou desrespeitosas ao aluno e possuem diversos serviços de apoio disponíveis aos professores e alunos. Nessas escolas, é intensa a articulação entre família, comunidade/escola e instituições especializadas, procurandose sempre o cumprimento da função escolar com todos os alunos, independente de suas condições (MINAS GERAIS, 2003, p. 2).

Mazzotta (1993) é incisivo ao afirmar que é preciso criar condições para que os alunos com necessidades educacionais especiais, matriculados em escolas comuns, usufruam de: currículo especial ou currículo comum com as devidas alterações, uso de material, equipamentos e aparelhos específicos e, sobretudo, professores competentes e capacitados para a educação inclusiva. O magistério, na educação inclusiva, deve partir do pressuposto de que ensinar a todos, não significa ensinar tudo, da mesma forma a todos, com os mesmos objetivos e formas de avaliação. É preciso considerar as diferenças e é equivocada a posição

${ }^{4}$ Constata-se que é habitual, inclusive, em documentos normativos, ser utilizada a terminologia "escola regular". Entretanto, segundo informação dada em palestra, pelo professor Carlos Roberto Jamil Cury, deve-se utilizar a terminologia "escola comum", pois "escola regular" parte do pressuposto de que as outras escolas, como, por exemplo, a escola especial, seriam irregulares. 
de que "a diferença/deficiência por si mesma, traria subsídios para ensinar os professores a lidar com a mesma" (MAGALHÃES, 2006, p. 367).

Pode-se afirmar que a maioria dos autores considera importante que o professor seja capacitado para a educação inclusiva. Para exemplificar, expõemse posições de três pesquisadores da área em apreço. "A formação dos professores para a educação especial, tendo como foco a inclusão, indica a formação docente como elemento-chave para a mudança da escola" (MICHELS, 2006, p. 491). Para Mazzotta (1993, p. 41), a educação especial e a situação da excepcionalidade da educação escolar, mediadas pela educação comum, "dependem, fundamentalmente, da qualidade ou da competência dos professores comuns e especializados". Omote (2003) avalia que os professores do ensino comum necessitam de formação para serem bons educadores, com conhecimento e experiência indispensáveis à educação dos alunos com necessidades educacionais especiais, para saberem usar os recursos e os procedimentos metodológicos especializados,e para decidirem sobre os conhecimentos e experiências que devem ser a eles proporcionados.

A formação de professores inclusivos deve se embasar:

[...] na concepção construída ao longo de toda a história de atendimento ao deficiente, de que cada deficiência constitui uma categoria específica, distinta da de pessoas não deficientes e das de outras deficientes. Nessa concepção, cada categoria de deficientes tende a ser revista como se apresentasse necessidades peculiares e próprias de seus integrantes, recursos humanos, materiais e metodológicos específicos e de uso exclusivo (OMOTE, 2003, p. 158).

As autoras deste trabalho consideram relevante a capacitação dos professores para a educação inclusiva, tanto para assegurar aos referidos alunos o direito a uma educação de melhor qualidade quanto para valorizar o professor em sua prática cotidiana, "reconhecendo-o como um profissional que, consciente de seus deveres, busca maior envolvimento com seu trabalho, objetivando o desenvolvimento dos seus alunos" (CURY, 2005, p. 13).

Contudo, a educadora Maria Tereza Égler Mantoan, em entrevista concedida à Revista Nova Escola, enfatiza que a capacitação do professor não se faz necessária: "Um professor, sem capacitação, pode ensinar alunos com deficiência, pois o papel do professor é ser regente de classe e não especialista em deficiência" (CAVALCANTE, 2005, p. 24). Para essa autora, as diferenças não precisam ser levadas em conta, pois a necessidade especial do aluno não é princípio relevante para a aprendizagem.

As pesquisadoras responsáveis por este artigo discordam da posição de Mantoan, pois consideram que é na escola e na sala de aula que as diferenças, 
geralmente, se tornam mais evidentes, exigindo dos professores conhecimentos mais densos sobre as especificidades e peculiaridades dos alunos, fato esse que requer formação específica. Assim, elas consideram que a capacitação de professores para a educação inclusiva é muito importante para promover a compreensão e a vivência do paradigma da diversidade, para a construção de uma nova proposta educacional, que atenda a todos os alunos, em suas especificidades e diferenças.

Essa formação deve oferecer aos alunos, futuros professores, uma clareza quanto aos seus objetivos e especificidades do ensino, levando em conta as condições socioeconômicas dos alunos, suas diferenças, as histórias de suas culturas e seus pertencimentos a um determinado contexto (SEVERINO, 2003).

A escola continua sendo o lócus preferencial da construção e da sistematização do conhecimento e, por mais que os conteúdos sejam flexibilizados para atender às diferenças, continua-se trabalhando com o conhecimento formal. E é esse conhecimento que os alunos com necessidades educacionais especiais devem apreender e dele se beneficiar, fazendo as adaptações necessárias, pois "estamos partindo do pressuposto de que o objetivo precípuo das atividades que se realizam na rede regular de ensino, com qualquer aluno, seja a escolarização formal" (OMOTE, 2003, p. 193).

Ressalta-se que, além da capacitação no âmbito da formação inicial, é fundamental, conforme recomendam a Resolução CNE/CEB n. 2/2001 e o Plano Nacional da Educação (2001), que os docentes tenham oportunidade de cursar a educação continuada, pois o conhecimento sempre se renova, assim como as determinações normativas e as condições objetivas de trabalho com alunos que apresentam necessidades educacionais especiais. O Plano Nacional de Educação estabelece as seguintes metas:

[...] Generalizar, em cinco anos, como parte dos programas de formação em serviço, a oferta de cursos sobre o atendimento básico a alunos especiais para os professores em exercício na educação infantil e no ensino fundamental, utilizando a TV Escola e outros programas de educação a distância [...] assegurar a inclusão, no projeto pedagógico das unidades escolares, do atendimento às necessidades educacionais especiais de seus alunos, definindo os recursos disponíveis e oferecendo formação em serviço aos professores em exercício. (BRASIL, 2001, p. 66-67).

Além da carência ou deficiência das formações inicial e continuada de professores para a educação inclusiva, outras questões afetam o trabalho docente. Assim, muitos autores têm denunciado o processo de intensificação do trabalho docente, inclusive, afirmando que a atual LDB, nos incisos I e II, do artigo 14, atribui novas e complexas tarefas aos professores. Além disso, 
para eles, o ingresso de alunos com necessidades educacionais especiais nas escolas comuns vem trazendo novas e maiores responsabilidades e desafios, para os quais os docentes não recebem o devido reconhecimento social e a melhoria de suas condições salariais e de trabalho.

O processo de inclusão nas escolas públicas no país não se difere do que vem ocorrendo na Rede Estadual de Ensino de Minas Gerais, como será relatado na pesquisa realizada pelas autoras deste trabalho. Tratando-se, especificamente, da pesquisa realizada, feita em uma escola comum da Rede Estadual de Ensino de Minas Gerais, menciona-se que os dispositivos legais (Orientação SD 01/2005, da SEE-MG) expõem sobre o atendimento educacional aos alunos com necessidades educacionais especiais na referida rede e enfatizam que o professor, ao receber esses sujeitos, pode, se necessitar, requerer assessoria de um professor especializado. Contudo, esse dispositivo legal é pouco divulgado e, na escola investigada, esse profissional não se fez presente no período da pesquisa.

Acredita-se que esse professor especializado que possui experiência de magistério em escolas especiais e formação para trabalhar com alunos com necessidades educacionais especiais poderia ter uma função ampliada e importante, na orientação dos professores e gestores das escolas comuns, sobretudo, assessorando-os nas especificidades da prática pedagógica do currículo e das avaliações para que se tornem mais acolhedores, flexíveis e promotoras tanto do sucesso escolar, quanto da formação para a cidadania.

\section{Metodologia}

\section{Caracterização da pesquisa}

Os objetivos visados pela investigação foram: investigar, na escola pesquisada, se as professoras eram capacitadas para a educação inclusiva e averiguar como vem se processando a inclusão de alunos com necessidades educacionais especiais, nessa escola.

\section{Caracterização do local da pesquisa}

A escola investigada, vinculada à Rede Estadual de Ensino de Minas Gerais, foi criada em 1945 e está localizada em Belo Horizonte, atendendo na época da pesquisa a 770 alunos dos anos iniciais do ensino fundamental. O corpo administrativo e pedagógico é formado pela diretora, vice-diretora, 3 supervisores, 3 funcionários e 28 docentes. Essa escola dispõe de uma área construída de $1.235 \mathrm{~m}^{2}$ e está situada em um espaço territorial de $3.699 \mathrm{~m}^{2}$. 


\section{Caracterização das participantes}

No Box, a seguir, são explicitados os dados coletados pelo questionário, e que traçaram o perfil das professoras da escola.

a) Sexo: 24 mulheres e 1 homem; b) Idade: 2 com idade entre 25 e 29 anos, 1 entre 30 e 39, 13 entre 40 e 49 e 9 têm mais de 50 anos; c) Estado civil: 12 professores são casados, 8 são solteiros, 3 divorciados, 1 viúvo e 1 separado; d) Número de filhos: 9 professores não possuem filhos, 5 têm 1, 5 têm 2 e 6 têm 3 ou mais filhos; e) Região de residência: 15 professores moram no próprio bairro da escola, 8 moram em bairros circunvizinhos e 2 moram na região norte da cidade; f) Atividades de lazer/cultura: 22 professores assistem televisão, 21 leem livros, 19 frequentam cinema, 16 leem revistas e jornais e 15 frequentam teatro; g) Uso de computador: 4 professores não usam, 20 usam em casa, 3 no trabalho, 2 em lan house e 1 em casa de amigos; h) Motivo do uso do computador: 19 professores usam para pesquisa, 12 para divertimento e 1 para outros fins; i) Atividade exercida na escola: 22 professores são regentes, 1 é regente eventual, 1 é professor de educação física e 1 de ensino religioso; j) Turnos de trabalho: 20 professores trabalham em 2 turnos e 5 em um único turno; $\mathrm{k}$ ) Tempo de experiência no magistério: 15 com mais de 20 anos; 4 entre 17 e 20 anos; 2 entre 13 e 16 e 4 entre 5 e 8 anos; 1) Modalidade de ensino na qual atua: 25 professores atuam nos anos iniciais do ensino fundamental, 1 atua também nos anos finais, 1 na educação especial e 1 na EJA; m) Atuação em outras funções educacionais: 4 professores atuam na rede estadual, 1 na rede municipal e 1 na rede particular; n) Escolaridade: 24 têm curso superior e 1, o ensino médio; o) Formação: 16 professores são formados em Pedagogia, 5 em Normal Superior, 2 em outras licenciaturas, $1 \mathrm{em}$ Educação Física e 1 em Magistério de nível médio; p) Pós-graduação: 10 possuem e 15 não possuem; q) Tempo de conclusão da graduação: 8 têm entre 1 e 4 anos, 4 têm entre 5 e 8 anos, 2 têm entre 9 e 12 anos, 7 têm entre 13 e 16 anos, 2 têm entre 17 e 20 anos e 2 têm mais de 20 anos; r) Currículo da graduação com a disciplina de Inclusão: 6 tiveram e 19 não tiveram; s) Falta dessa disciplina na graduação afeta o trabalho: 24 responderam positivo e 1, negativo; t) Participação em formação continuada: 5 professores disseram participar mais de uma vez por ano, 5 participam uma vez por ano, 14 eventualmente e 1 nunca participou; u) Currículo da formação continuada com a disciplina sobre Inclusão: 7 professores responderam que tiveram e 17 não tiveram; v) A disciplina deve fazer parte do currículo: 24 professores responderam positivo e 1, negativo; w) Conhecimento sobre a legislação relativa à Inclusão: 12 professores disseram que conhecem e 13 não; x) Aluno com necessidade especial: 18 professores responderam que têm ou já tiveram esse tipo de aluno e 7 não têm; y) Suprir os conhecimentos a respeito de PNEE: 22 professores responderam que é responsabilidade do próprio professor, 12 disseram que é da própria escola e 23 responderam que é da rede de ensino onde ele atua; z) Infraestrutura da escola: todas as professoras concordaram em dizer que a escola não tem infraestrutura para receber o aluno especial. 
Procedimentos de coleta dos dados

Metodologicamente, foi feita uma investigação "Quali-Quanti", sendo aplicado um questionário a 25 docentes da escola, para desenhar o perfil desses sujeitos. No que tange à pesquisa qualitativa, foram entrevistadas 10 professoras, a diretora da escola e a gerente da Diretoria de Educação Especial, da Secretaria Estadual de Educação (SEE-MG). A análise de conteúdo foi utilizada para interpretar os dados coletados pelas entrevistas.

\section{Resultados e discussão}

Apresentação das oito categorias identificadas nas falas das docentes Inclusão de alunos com necessidades educacionais especiais na escola pesquisada

Como se vem constatando em muitas pesquisas, e nesta também, as professoras se mostraram favoráveis e sensibilizadas para trabalhar com esses alunos, conforme se pode perceber, nestas falas: "aqui só se faz a socialização, impossível trabalhar conteúdos; não fomos capacitadas, não seguiram a lei que manda qualificar, fica difícil trabalhar com os especiais"; "difícil, nós não fomos treinados, a escola não está adaptada"; "tenho 30 alunos com 'n' problemas de aprendizagem e de disciplina, como dar atenção aos especiais?"; "falta tudo, as crianças não têm apoio, a gente não dá conta e elas acabam se sentindo reprimidas, excluídas".

O trabalho com os alunos que apresentam necessidades educacionais especiais

No que se refere ao trabalho com alunos com necessidades educacionais especiais, constatou-se que todas as docentes não tinham experiência e, apesar de manifestarem boa vontade, explicitaram ter dificuldades em "lidar" com os mesmos. Essas dificuldades eram decorrentes, principalmente, do fato de não terem sido capacitadas para promover a inclusão.

\section{Conhecimento da legislação sobre a inclusão}

A respeito do conhecimento da legislação sobre a inclusão, segundo Cury (2005), os professores e mesmo muitos gestores desconhecem os documentos normativos, relativos à inclusão de alunos com necessidades escolares especiais, nas escolas comuns. Os depoimentos coletados reforçaram a posição desse autor: "eu tive pouquíssimas informações na graduação"; "é, sei alguma coisinha que aprendi em cursos, que não foram lá muito bons"; "eu estudei um pouco, sozinha"; "eu nunca pensei passar tanto aperto, não conheço a lei, não fui treinada, não sei lidar". 
Relação dos alunos com os colegas que apresentam necessidades educacionais especiais

A quarta categoria se refere ao relacionamento dos alunos com seus colegas com necessidades educacionais especiais.

Segundo Omote (2003), para se construir uma escola inclusiva, é preciso que a sociedade seja inclusiva. Essa é, sem dúvida, uma premissa verdadeira, pois o preconceito e a discriminação são gerados na sociedade e nas famílias.

As professoras declararam que a sensibilização dos alunos da turma tem de ser constante e que esse trabalho vem obtendo resultados positivos: "eu acho que os colegas são carinhosos com os especiais, desde que eles não sejam agressivos"; "no início, eles começaram a caçoar do anão e ele chorava, mas trabalhei com eles e, agora, aceitam"; "a menina com Down é até protegida"; "aceitam, agora, se algum especial é agressivo comigo, ou com os colegas, eles não gostam".

\section{Perfil do professor inclusivo}

Nesta categoria, foram esses os depoimentos das docentes: "o professor tem de ter aquela habilidade, enfrentar o desafio"; "não é qualquer um que consegue, pior ainda, pelo fato de não ter capacitação"; "muitos colegas e mesmo eu, não temos aquela disposição, aquela vontade de dar o máximo de si"; "a gente até pode ter vontade, mas pensa, com um montão de alunos, sem ter capacitação, e ter de cuidar dos especiais, é muita carga, trabalho demais, além de tudo, a gente tem trabalho demais, como ter paciência e tempo para lidar com esses alunos?"; "de uns anos para cá, o nosso trabalho dobrou, as férias diminuíram, então, como ter o perfil para trabalhar com alunos que precisam de atenção redobrada?"; "eu até procuro ter esse perfil, apesar da sobrecarga de trabalho, salário baixo, sala cheia, é difícil, a escola não é adaptada, os banheiros não são adaptados. Acredita, fui observando que um aluno anão não ia ao banheiro, ficava sem fazer xixi o tempo todo, tive de pedir para fazer um banquinho para ele alcançar o vaso sanitário".

Constata-se, por esses depoimentos, que ter boa vontade e sensibilidade não bastam, pois, além da carência de capacitação, a falta de adaptação da infraestrutura da escola e a intensificação do trabalho docente dificultavam o processo de inclusão na escola.

\section{Apoio da SEE}

As falas de todas as professoras evidenciaram que esse apoio não tem sido satisfatório e reclamaram, também, da dificuldade que vêm encontrando 
para se qualificarem. Esses depoimentos estão em consonância com o que vêm reiterando muitos pesquisadores: o discurso apologético da inclusão não atinge o chão da escola.

\section{Evasão de alunos com necessidades educacionais especiais}

Segundo Michels (2006), nem sempre, a escola comum tem as condições necessárias, tanto no nível de "recursos humanos capacitados" quanto no da infraestrutura e dos recursos didático-pedagógicos, que poderiam contribuir para viabilizar a educação inclusiva. Por isso, muitos alunos se evadem, conforme explicitam essas falas: "a mãe achou que o menino estava sofrendo aqui"; "o menino saiu, terminou a escolaridade de qualquer modo, não adianta ficar, pois ele não tem apoio para desenvolver mais"; "o aluno voltou para a escola especial, a gente procura integrar, cuidar, mas não dá conta"; "sei que a inclusão é importante, mas fazer como, com que condição? Então, muitos voltam para a escola especial, que tem mais condições".

Responsabilidade pela capacitação dos docentes pesquisados

É interessante ressaltar que, embora muitos documentos normativos nacionais mencionados - Constituição Federal de 1988, LDB de 1996, Plano Nacional da Educação de 2001 - determinarem a capacitação dos professores para a educação inclusiva, esse preceito não vem sendo, geralmente, cumprido.

As falas das entrevistadas indicaram que a Secretaria de Educação deveria se responsabilizar pela capacitação: "eu acho que a SEE deveria nos apoiar e dar curso"; "a SEE não capacita e é dela a responsabilidade de nos capacitar"; "eu acho que a secretaria deveria dar curso".

\section{Diretora da DESP (Diretoria de Educação Especial)}

Quanto à "fala da Diretora da DESP", pode-se afirmar que ela se posicionou, via de regra, de modo contrário ao que os professores declararam, como evidenciam pequenos fragmentos de seu depoimento:

- Quanto à inclusão na escola comum: "para mim existe muito preconceito dos professores a respeito de inclusão; muitos acham que os deficientes deveriam ficar nas escolas especiais"; "com o Projeto Incluir e nossos textos e orientações, entretanto, observo que tem melhorado, mas há reclamações, querem mais recursos, mas eles são poucos".

- Quanto à formação de professores: "bem, o Projeto Incluir tá ocorrendo no interior, em $\mathrm{BH}$, abordando a capacitação para lidar com alunos surdos e 
cegos; não conseguimos atender a todo interior, mas tá indo"; "damos formação para os professores, mas em Belo Horizonte o processo não tá indo bem; também não há interesse dos professores. É verdade que tem pouquíssimas vagas, mas o interesse é pequeno, também".

- Quanto ao apoio da Secretaria: "damos todo apoio, conscientizamos o pessoal da escola, temos um apostila que mostra as propostas do Projeto Incluir. Esse projeto prevê a remoção das barreiras arquitetônicas, a acessibilidade tecnológica, a formação em rede de apoio, na qual em cada município será oferecido atendimento especializado; estamos prevendo cursos de 120 horas, por área de deficiência. Além disso, as Universidades vão fazer capacitação".

\section{Depoimento da diretora da escola}

A diretora da escola foi sucinta no seu depoimento; como se evidenciam excertos da sua fala:

[...] eu não recebi na graduação e nem em outros cursos que fiz, nenhum tipo de formação para trabalhar com a inclusão; conheço algumas leis a respeito do ECA, do Conselho Tutelar, da Promotoria, mas leis da inclusão não; trabalhar com alunos especiais, aqui na escola, é difícil; até que eu procuro ajudar e é uma experiência inovadora, rica, mas difícil, especialmente para mim, porque o trabalho na direção é estafante, muito burocrático, demandando inúmeras atividades. Aqui, tem casos variados de deficiência; tem casos de crianças com dificuldade de falar, ou que não falam e a gente fica tentando comunicar, mas não consegue entender. Outro dia, um menino com esse problema procurava se comunicar comigo, e eu nem en-tendia nada, mas um coleguinha compreendia e me ajudou. Teve um caso de um aluno, não sei o que ele tinha, mas babava muito e os meninos ca-çoavam, a gente tentou sensibilizar, mas as crianças continuavam chamando-o de babão.

\section{Considerações finais}

Os dados coletados evidenciaram que, na escola pesquisada, o processo de inclusão tem encontrado muitas dificuldades para se concretizar. Assim, verificou-se que as professoras e a diretora se mostraram conscientizadas e sensibilizadas da necessidade de incluir os alunos com necessidades educacionais especiais, mas as condições objetivas inviabilizaram ou dificultaram o desenvolvimento de uma real inclusão desses sujeitos. Constatou-se que muitos fatores entravaram o processo inclusivo: carência de rampas e de banheiros adaptados; falta de capacitação dos docentes; precariedade do apoio dado pela SEE; desconhecimento do diagnóstico das deficiências e de como lidar com elas; 
número elevado de alunos na sala de aula; inexistência do professor especializado para assessorar os docentes; intensificação do trabalho docente.

As falas das professoras desconstruíram tanto os discursos dos gestores públicos, entre eles da SEE de Minas Gerais, quanto os discursos normativos e os da mídia, que vêm apregoando os inúmeros benefícios alcançados pela inclusão, nas escolas comuns, dos alunos com necessidades educacionais especiais. Dessa forma, esvai-se no ar a apologia feita pela SEE e, sobretudo, pelos meios televisivos, que se traduz em considerar a inclusão como uma panaceia, capaz tanto de livrar os alunos com necessidades educacionais especiais da suposta segregação das escolas especiais quanto de promover suas inserções socioprofissionais e o acesso à cidadania.

As autoras deste trabalho são favoráveis à inclusão, desde que ela não se constitua como uma "inclusão-excludente". O modo como vem se processando a inclusão em diversas escolas pode levar essas pesquisadoras a "engrossarem o coro" dos que consideram a racionalidade financeira como pressuposto básico das políticas públicas de inclusão.

Finalmente, como este artigo dá ênfase à formação do professor para a educação inclusiva, considera-se que essa capacitação é importante, pois o docente tem um papel fundamental na promoção de uma real mudança na escola comum e inclusiva.

Para Michels (2006), se o professor não for capacitado e se não forem disponibilizados recursos educacionais e infraestruturais, o discurso da inclusão e a necessária aceitação das diferenças não se consolidam, ou seja, a "narrativa" do respeito às diferenças pode instaurar uma "educação diferente", mas não adequada aos mencionados alunos, compensando, apenas, as diferenças sociais e reduzindo os custos.

\section{REFERÊNCIAS}

BALL, S. Education reform: a critical and post-structural approach. Buckingham: Open University Press, 1997.

BRASIL. Lei n. 4.024 de 20 de dezembro de 1961. Estabelece as Diretrizes e Bases da Educação Nacional. Diário Oficial da União, Brasília, 27 dez. 1961.

. Lei de Diretrizes da Educação Nacional n. 5.692, de 11 de agosto de 1971. Dispõe sobre as Diretrizes e Bases para o ensino de $1^{\circ}$ e $2^{\circ}$ graus. Diário Oficial da União. Brasília, 12 ago. 1971. 
. Constituição da República Federativa do Brasil. Brasília: Senado Federal, 1988. $168 \mathrm{p}$.

. Lei n. 7.853 de 24 de outubro de 1989. Dispõe sobre o apoio às pessoas portadoras de deficiência, sua integração social, sobre a Coordenadoria Nacional para Integração da Pessoa Portadora de Deficiência (CORDE), institui a tutela jurisdicional de interesses coletivos ou difusos dessas pessoas, disciplina a atuação do Ministério Público, define crimes, e dá outras providências. Diário Oficial da União, Brasília, 25 out. 1989.

. Ministério da Educação e do Desporto. Decreto $n .914$ de 6 de setembro de 1993. Estabelece em seu artigo $5^{\circ}$ o que são Diretrizes da Política Nacional para a Integração da Pessoa Portadora de Deficiência. Brasília, 1993.

. Ministério da Educação e do Desporto. Portaria n. 1.793, de dezembro de 1994, que resolve recomendar a inclusão da disciplina "Aspectos éticopolítico-educacionais da Normalização e Integração da Pessoa Portadora de Necessidades Especiais”. Brasília, 1994.

. Senado Federal. Declaração Mundial de Salamanca e Linhas de ação sobre Necessidades Educativas Especiais: acesso e qualidade. Brasília: CORDE, 1994.

. Lei n. 8.069 de 13 de julho de 1990. Dispõe sobre o Estatuto da Criança e do Adolescente e dá outras providências. Diário Oficial da União, Brasília, 16 jul. 1996a.

. Lei n. 9.394 de 20 de dezembro de 1996. Estabelece as Diretrizes e Bases da Educação Nacional. Diário Oficial da União, Brasília, 23 dez. 1996b.

. Ministério da Educação e do Desporto. Parâmetros Curriculares Nacionais. Adaptações Curriculares - Estratégias para a Educação de Alunos com Necessidades Educacionais Especiais. Brasília, 1998.

. Lei n. 10.172, de 09 de janeiro de 2001. Aprova o Plano Nacional de Educação e dá outras providências. Diário Oficial da República Federativa do Brasil, Poder Executivo, Brasília, 2001.

. Parecer CNE/CEB n. 17/2001, aprovado em 03 de julho de 2001. Dispõe sobre as Diretrizes Nacionais para a Educação Especial na Educação Básica. Brasília: MEC/SEESP, 2001. 
. Resolução CNE/CEB n. 02 de 11 de setembro de 2001. Institui as Diretrizes Nacionais para a Educação Especial na Educação Básica. Brasília, 2001.

. Decreto legislativo n. 3.956 de 08 de outubro de 2001. Promulga a Convenção Internacional para Eliminação de Todas as Formas de Discriminação contra as Pessoas Portadoras de Deficiência. Diário Oficial da União, Brasília, 09 out. 2001.

CAVALCANTE, M. Inclusão é o privilégio de conviver com as diferenças. Entrevista com Maria Tereza Égler Mantoan. Revista Nova Escola, São Paulo, n. 182 , p. 24-26, abril/maio 2005.

CURY, Carlos R. J. Os fora de série na escola. Campinas: Armazém do Ipê (Autores Associados), 2005. 89 p.

MAGALHÃES, R. C. B. P. Processos formativos e saberes docentes em tempos de inclusão: apontamentos a partir de contribuições da educação especial. In: SILVA, A. M. M. et al. Novas subjetividades, currículo, docência e questões pedagógicas na perspectiva da inclusão social. Recife: Bagaço, 2006.

MAZZOTTA, M. J. S. Trabalho docente e formação de professores de educação especial. São Paulo: EPU, 1993. 146 p.

MICHELS, M. H. Gestão, formação docente e inclusão: eixos da reforma educacional brasileira que atribuem contornos à organização escolar. Revista Brasileira de Educação, v. 11, n. 33, p. 406-560, set./dez. 2006.

MINAS GERAIS. Parecer n. 424/2003, aprovado em 27.5.03. Propõe normas para a Educação Especial na Educação Básica, no Sistema Estadual de Ensino de Minas Gerais. Belo Horizonte: Imprensa Oficial, 2003.

. Secretaria de Estado da Educação - Subsecretaria de Desenvolvimento. Orientação SD 01 de 08 de abril de 2005. Belo Horizonte: Secretaria de Estado da Educação, 2005.

OLIVEIRA, M. A. M.; AMARAL, C. T. O aluno especial na escola regular: inclusão ou exclusão? In: REUNIÃO ANUAL DA ANPED, 27., Caxambu, 2004. Anais... 16 p.

OMOTE, S. A formação do professor de educação especial na perspectiva da 
inclusão. In: BARBOSA, Raquel L. L. (Org.). Formação de educadores: desafios e perspectivas. São Paulo: UNESP, 2003. p. 153-169.

SEVERINO, A. J. Formação e prática do educador. In: Educação, sujeito e história. São Paulo: Olho D’água, 2003.

UNESCO. Declaração Mundial de Educação para Todos e Plano de Ação para satisfazer as Necessidades Básicas de Aprendizagem. Jomtien - Tailândia, 1990.

XAVIER, A. G. P. Ética, técnica e política: a competência docente na proposta inclusiva. Integração. Ministério da Educação, Secretaria de Educação Especial. Brasília-DF, ano 14, n. 24, p. 18-21, 2002.

Texto recebido em 17 de fevereiro de 2010.

Texto aprovado em 10 de abril de 2010. 
